\title{
Don't Get Burned
}

\section{PREVENTING BURNOUT IS KEY FOR PROFESSIONALS AND THEIR FIRMS}

\section{By Lori Pizzani}

We've all experienced variations of stress: mental and physical fatigue, loss of focus, a lack of interest, emotional upheaval, feelings of insecurity or constant edginess, and eventually pure exhaustion. These are some of the classic symptoms of stress that, if left unchecked for an extended period of time, can lead to full-blown burnout.

Before you fully accept

Chronic stress can lead to burnout and feelings of emotional exhaustion, a negative attitude, and a decrease in job accomplishments.

Finding your individual work-life balance is critical to coping with stress and avoiding burnout.

To mitigate job-related stress, take periodic breaks, schedule out-of-office down time, pursue outside hobbies/passions, get the sleep you need, and stay positive.

Though a number of factors contribute to the problem, a primary reason appears to be workers at all levels feeling alienated, insecure, misunderstood, and undervalued.

\section{THE ROAD TO BURNOUT}

Maslach points out that "chronic stress can be emotionally draining and lead to burnout." Burnout is defined as a "psychological syndrome" of emotional exhaustion, depersonalization (such as a negative, cynical, callous attitude), and reduced personal accomplishment (the tendency to evaluate oneself negatively). The burnout syndrome often causes emotional exhaustion; as workers feel emotionally overextended, emotional resources become depleted. Consequently, even once-stellar employees often feel unhappy with themselves and dissatisfied with their job accomplishments. This can lead to increased job turnover, absenteeism, low morale, personal dysfunction, and even an increase in substance abuse among employees.

Research led to Maslach's development of the Maslach Burnout Inventory (MBI), which incorporates three subscales used to assess the different aspects of an individual's burnout. Respondents self-administer the assessment, assigning points to various statements of personal feelings. "The MBI is a research measure. It is not a clinical tool used to diagnose burnout," Maslach says. "Burnout is not a disease but an experience at work."

It might be easy to blame stressed workers for not appropriately reining in negative emotions and adequately diffusing stress before it turns into burnout. But Maslach asserts that employer organizations must be held accountable for causing work stress and burnout.

\section{EMOTIONALLY SUPERCHARGING}

Getting in touch with the origins and causes of one's own emotions and then learning how to understand and manage those emotions is part of the concept behind emotional intelligence (EQ). "EQ is your ability to recognize and understand your emotions and use this awareness to manage yourself and your relationships with others," says Andrew Snyder, a psychotherapist and executive coach based in Honolulu, Hawaii. This includes being aware of how and why emotions drive our behavior and can have a positive or negative impact on those around us, especially when we are stressed.

EQ includes several components, such as self-awareness and self-management, that can lead individuals to determine what they are doing and why and help them manage emotions, feelings, and behaviors. "When we bring the subconscious to the conscious, we make better decisions, and we can work more harmoniously," Snyder explains. "It helps build resiliency; adaptability is key." But recognizing what doesn't constitute EQ is just as important as understanding what does. "EQ doesn't mean wearing your emotions on your sleeve," Snyder counsels. Rather, it helps people make better choices, can foster better health, and improves relationships with others, both at work and at home.

\section{WORK-LIFE BALANCE}

"Burnout and poor work-life balance are two of the greatest causes of stress in the workplace," says David Scarola, vice president at The Alternative Board (TAB) in Westminster, Colorado. TAB, which provides business services, conducted a work-life-balance survey across all industries in 2014 and found that $82 \%$ of business owners surveyed were working more than 40 hours per week. (Only 44\% wanted to.) It also found that less than one-quarter (24\%) felt no negative effects from work-related stress. Overworked business owners reported feelings of impatience, insomnia, forgetfulness, mood swings, restlessness, boredom, and temper outbursts. "Strategic planning that incorporates taking time off is one of the best solutions for combating a poor work-life 
balance," Scarola says. "Schedule days, or even hours, of time off the way you schedule meetings or important events."

Work can easily consume your life, especially if you (at least used to) love what you do. But it's important to remember that even a stress-ridden job is just one aspect of your life. Fitting your work into your broader life, not necessarily making it the center of your universe, is critical to busting stress and putting you on a path to contentment.

"Take charge! You are the CEO of your work life," says Sally Anne Giedrys, a life and career coach and founder of Whole Life Strategies Coaching in Portland, Oregon. "A sustainable work-life balance is critical to our happiness and well-being." We must each define this for ourselves and find our personal balance.

"Work-life balance is the key to ultimate success, peak productivity, and best of all, happiness," stresses Tasha Mayberry, author, co-founder, and president of Social Media 22 in Milford, Connecticut, a public relations/marketing/ web-design firm. She suggests making the time to live life more fully, which should include taking "me moments"breaks from work multiple times each day. Mayberry recommends finding a hobby or a passion to explore and setting non-negotiable rules, such as establishing no-technology zones in your home and forbidding emails after a certain hour, so that family time prevails. Even during the day, she blocks out "email-free" hours so she can get projects done without interruptions.

\section{PRACTICAL COPING MECHANISMS}

Regular meditation, yoga, an exercise routine, and even massage therapy can aid in busting stress. However, there are other coping tools that individuals can deploy within their everyday routines.

"One aspect of burnout is intellectual exhaustion," says Nancy B. Irwin, a psychologist in Los Angeles, California. Allowing your brain muscles to relax in your free time can be vital. "Schedule one or more outside events in your weekly calendar. It will be the most important appointment you have-with yourself."

She suggests watching a comedy movie or TV show or going to a comedy club. "Laughter lifts the mood and allows endorphins-the happy hormones-to flow again." She also suggests diving into art, which can be very healing, whether you jump on the adult-coloring-book trend, take an art class, or simply paint by numbers with your children. Enjoy music? Go to a concert, lose yourself in your favorite music in the car or at home, or sing and play music yourself, Irwin counsels. Lastly, she recommends spending time with petsanimals can be therapeutic to the soul-and connecting with Mother Nature by taking long hikes without your cell phone.

"Schedule two separate 15-minute walking breaks during the day, and put them in your calendar so that you treat them like an actual meeting," says Amy Cooper

Hakim, an organizational psychology practitioner and principal consultant at The Cooper Strategic Group in Boca Raton, Florida. If it's not possible to walk out in the fresh air, walk the halls of your office building, she says. "The key is to get up and moving. This action wakes up your body and your mind and leaves you refreshed and ready to tackle the next item on your to-do list." In addition, she suggests ensuring that each and every day you do one thing that is just for you. "Make yourself a priority, and you'll feel like your life has more purpose and meaning."

Finally, Hakim recommends getting enough rest each night in order to mitigate stress. "When you are well rested, your brain will be sharper, and you will make better choices at work and perform more efficiently." Achieving quality sleep is even more important, says Maelisa Hall, a licensed psychologist, career counselor, and founder of QA Prep and Hall Counseling Group in Los Angeles, California. She recommends "using blackout curtains to create a very dark room, limiting your caffeine intake after noon, and doing five minutes of exercise upon waking to get your cortisol flowing and let your melatonin know to slow down."

\section{ACCENTUATE THE POSITIVE}

Many find it's a constant struggle to fight job stress. Adding some well-considered positivity into your day often offsets even a flood of negative emotions.

"Practice positive gossip," suggests Linda Swindling, an executive coach/workplace-communications expert, author, and president of Journey On, a Dallas, Texas-based development/training company. "Become the bearer of good news; share others' successes and forget your own ego while you build up everyone else's." She also suggests volunteering your time and expertise to mentor others who would benefit, including helping new employees reach their potential.

Don't forget to reward yourself, something we as a society don't do enough, says Jessica May Tang, a corporate wellness coach and founder of Damon Wellness Consulting in Los Angeles, California. "The more you positively reinforce the accomplishment of a goal, for instance, your brain patterns change so that activities you're working toward become more enjoyable."

While positivity can be a useful strategy, learning to say no is equally important. "Prioritize your activities based on value, and say no or not now to those that don't make the cut for that day, week, or month," suggests Dawn Roberts, owner of Dawn Roberts Consulting of Houston, Texas. "Otherwise, you'll constantly be at the mercy of other people's priorities and living in chaos and stress."

KEEP GOING

"Insighter Trading," CFA Institute Magazine (December 2016) [www.cfapubs.org]

CFA Institute Meditation Guide for Investment Professionals: http://cfa.is/2jzUHGg

"The Inefficient Frontier: Work-Life Balance," CFA Institute Magazine (January/February 2014) [www.cfapubs.org]
Lori Pizzani is an independent business and financial services journalist based in Brewster, New York. 